\section{A) Check for updates}

Cite this: Food Funct., 2019, 10, 6459

\title{
Antidiabetic effects of extracts of red and yellow fruits of cornelian cherries (Cornus mas L.) on rats with streptozotocin-induced diabetes mellitus
}

\author{
Olha Dzydzan, (D) a Ivanna Bila, ${ }^{a}$ Alicja Z. Kucharska, (D) ${ }^{b}$ Iryna Brodyak (D) *a and \\ Natalia Sybirna (iD ${ }^{\text {a }}$
}

The effects of extracts of red and yellow fruits of cornelian cherries have been evaluated in rats with streptozotocin-induced diabetes mellitus. Cornus mas L. active compounds were analyzed by ultra-performance liquid chromatography coupled with electrospray ionization mass spectrometry (UPLC-ESIqTOF-MS/MS) in positive and negative ion modes and by HPLC-PDA, followed by the identification of iridoids, anthocyanins, phenolic acids and flavonols. Rats with type 1 diabetes mellitus were orally dosed with the extracts in amounts of $20 \mathrm{mg} \mathrm{kg}^{-1}$ of body weight for 14 days. The cornelian cherry extracts lowered blood glucose and improved glucose tolerance. The treatments significantly decreased the amount of glycated hemoglobin (by 25\%) and increased erythrocyte resistance to acid hemolysis. Importantly, only treatment with the extract of yellow fruits of the cornelian cherry increased the level of reduced glutathione and mean cell hemoglobin in diabetic rats. The active compounds of Cornus mas $L$. demonstrated the antidiabetic and antioxidant effects via the attenuation of hyperglycemia and inhibition of oxidative modifications of proteins and lipids, advanced glycation and oxidation protein formation or accumulation. The results suppose that cornelian cherries can be considered as a food supplement to alleviate diabetes mellitus and its complications.

Received 12th March 2019, Accepted 31st July 2019

DOI: $10.1039 /$ c9fo00515c rsc.li/food-function oxide radical $\left(\mathrm{O}_{2}^{-}\right)$, hydrogenperoxide $\left(\mathrm{H}_{2} \mathrm{O}_{2}\right)$, hydroxyl radical $\left(\mathrm{OH}^{-}\right)$and peroxynitrite $\left.\left(\mathrm{ONOO}^{-}\right)\right)$induce oxidative stress in diabetic animals and humans. ${ }^{9}$ Glucose auto-oxidation, the polyol pathway, protein glycation, and formation of advanced glycation end products (AGEs) and advanced oxidation protein products (AOPPs) are the major mechanisms that precede metabolic changes. ${ }^{10-12}$ Hyperglycemia increases the enzymatic conversion of glucose to polyalcohol sorbitol, using nicotinamide adenine dinucleotidephosphate (NADPH) that causes the depletion of NADPH and reduced glutathione (GSH). Subsequent loss of antioxidants and reduced equivalents causes higher sensitivity to oxidative stress. ${ }^{13,14}$ Thus diabetes is accompanied by an increase in lipid peroxidation, and a decrease in the amount of scavenging antioxidants and the activities of antioxidant enzymes. ${ }^{15,16}$

The search for remedies exhibiting hypoglycemic properties and being capable of correcting metabolic disorders and preventing oxidative stress, glycation and lipid peroxidation (LPO) processes under conditions of diabetes is essential nowadays. Functional food products have to influence most of those processes possessing antioxidant properties in order to be effective.

Currently, more than 400 plants, in different forms, are being used for hypoglycemic effects. The family of Cornaceae

\footnotetext{
Department of Biochemistry, Ivan Franko National University of Lviv, 79000 Lviv, Ukraine.E-mail: iryna_brodyak@yahoo.com; Tel: +380 322394788

${ }^{b}$ Department of Fruit, Vegetable and Plant Nutraceutical Technology, Wrocław University of Environmental and Life Sciences, 51-630 Wroctaw, Poland
} 
includes approximately 40 species. The best-known species of Cornus is the Japanese cornelian cherry (Cornus officinalis Sieb. et Zucc.). The main constituents of the C. officinalis exhibit a variety of biological effects: immunomodulatory and antimicrobial activity and lower blood glucose levels, exert positive effects on lipid metabolism, and possess antidiabetic effects. $^{15,17-20}$ Another species of the Cornaceae family Cornus mas L. is a native or cultivated plant in southern and central Europe and southwest Asia. Its fruits have been used for a long time in traditional cuisine as well as in folk medicine of many countries for the relief and treatment of many pathological conditions, especially of gastrointestinal and metabolic disorders, diarrhea, fever, and common cold. ${ }^{21,22}$ Little is known about the biochemical effects of extracts of red and yellow fruits of Cornus mas L. on diabetes, in comparison with C. officinalis. ${ }^{23,24}$ Extracts of red and yellow fruits of Cornus mas L. contain anthocyanins and iridoids in significant amounts and thus might have beneficial effects on diabetic animals. In the current study, we have investigated the effects of cornelian cherry extracts on fasting blood glucose and glucose clearance in the oral glucose tolerance test (OGTT), blood parameters and markers of oxidative stress in plasma of rats with STZ-induced DM.

\section{Materials and methods}

\subsection{Reagents}

Streptozotocin, 5,5'-dithiobis (2-nitrobenzoic acid), thiobarbituric acid, trichloroacetic acid, and 2,4-dinitrophenylhydrazine were from Sigma Aldrich $\mathrm{GmbH}$, Germany. Acetonitrile for liquid chromatography-mass spectrometry was purchased from POCh (Gliwice, Poland). Loganic acid (LA), loganin (L), sweroside (S), cyanidin 3-O-glucoside (Cy glc), 5-Ocaffeoylquinic acid (5-CQA, chlorogenic acid), caffeic acid (CA), $p$-coumaric acid ( $p$-CoA), ellagic acid (EA), quercetin 3-O-glucoside (Q glc), and kaempferol 3-O-glucoside ( $\mathrm{Kf}$ glc) were purchased from Extrasynthese (Lyon Nord, France). All other reagents were of analytical grade.

\subsection{Plant materials and preparation of cornelian cherry extracts}

Cornelian cherry fruits (Cornus mas L.) from 2 cultivars ("Yantarnyi" (yellow colour) and "Podolski" (red colour) were harvested in the Arboretum in Bolestraszyce, near Przemyśl, Poland. The plant materials were authenticated by Prof. Jakub Dolatowski (the Arboretum and Institute of Physiography in Bolestraszyce, Przemyśl, Poland), and adequate voucher specimens ("Yantarnyi" - BDPA 14131; "Podolski" - BDPA 10462) were deposited at the Herbariums of Arboretum in Bolestraszyce, Poland. Fruits were harvested in August and September 2016 and immediately frozen at $-20{ }^{\circ} \mathrm{C}$.

Frozen ripe fruits of the cornelian cherry (Cornus mas L.) $\left(20 \mathrm{~kg}\right.$ ) were shredded and heated for $5 \mathrm{~min}$ at $95{ }^{\circ} \mathrm{C}$ using a Thermomix (Vorwerk, Wuppertal, Germany). The pulp was subsequently cooled down to $40{ }^{\circ} \mathrm{C}$ and depectinized at $50{ }^{\circ} \mathrm{C}$ for $2 \mathrm{~h}$ by adding $0.5 \mathrm{ml}$ of Pectinex BE XXL (Novozymes A/S,
Denmark) per $1 \mathrm{~kg}$. After depectinization, the pulp was pressed in a laboratory hydraulic press (SRSE, Warsaw, Poland). The pressed juice was filtered and run through an Amberlite XAD-16 resin column (Rohm and Haas, Chauny Cedex, France). Impurities were washed off with distilled water, while pigments and iridoids were eluted with $80 \%$ ethanol. The eluate was concentrated under vacuum at $40{ }^{\circ} \mathrm{C}$. The solvent was evaporated using a Rotavapor (Unipan, Warsaw, Poland) and lyophilized (Alpha 1-4 LSC, Christ, Germany). As a result of drying, $30 \mathrm{~g}$ of freeze-dried lyophilisate was obtained. The extracts were analyzed by UPLCqTOF-MS/MS and HPLC-PDA.

\subsection{Identification and quantification of compounds of cornelian cherry extracts by the UPLC-qTOF-MS/MS and HPLC-PDA methods}

The UPLC-qTOF-MS/MS method was previously described by Kucharska et al. ${ }^{25}$ Identification of compounds was performed using an Acquity ultra-performance liquid chromatography (UPLC) system, coupled with a quadrupole-time of flight (Q-TOF) MS instrument (UPLC/Synapt Q-TOF MS, Waters Corp., Milford, MA, the USA), with an electrospray ionization (ESI) source. Separation was achieved on an Acquity BEH C18 column $(100 \mathrm{~mm} \times 2.1 \mathrm{~mm}$ i.d., $1.7 \mu \mathrm{m}$; Waters). Iridoids, phenolic acids, and flavonols were explored in the negative mode while anthocyanins - in the positive mode before and after fragmentation.

The HPLC-PDA method was previously described by Kucharska et al. ${ }^{25}$ The quantification analysis was performed using a Dionex (Germering, Germany) system, equipped with a diode array detector model Ultimate 3000, a quaternary pump LPG-3400A, an autosampler EWPS-3000SI, and a thermostated column compartment TCC-3000SD, and controlled by Chromeleon v.6.8 software (Thermo Scientific Dionex, Sunnyvale, CA, USA). A Cadenza Imtakt column C5-C18 $(75 \times 4.6 \mathrm{~mm}, 5 \mu \mathrm{m})$ was used. Iridoids were detected at $245 \mathrm{~nm}$, anthocyanins at $520 \mathrm{~nm}$, phenolic acids and their derivatives at $320 \mathrm{~nm}$, ellagic acid at $254 \mathrm{~nm}$, and flavonols at $360 \mathrm{~nm}$. Loganic acid and cornuside were expressed as loganic acid, loganin, sweroside, and secoxyloganin as loganin, anthocyanins as cyanidin 3-O-glucoside, caffeoylquinic acid derivatives as 5-O-caffeoylquinic acid, $p$-cumaric acid derivatives as $p$-cumaric acid, quercetin derivatives as quercetin 3-O-glucoside, and kaempferol 3-O-galactoside as kaempferol 3-O-glucoside. The results were expressed as $\mathrm{mg}$ per $100 \mathrm{~g} \mathrm{dw}$.

\subsection{Animal experiments}

2.4.1 Induction of diabetes mellitus in rats. Wistar male rats with starting weight $120-130 \mathrm{~g}$ were used for all experiments. Animals were handled in accordance with the Ethics Committee of the Department of Biochemistry, Ivan Franko Lviv National University, Ukraine and the experiment carried out on the animals complied with the Directive 2010/63/EU of the European Parliament and the Council of 22.10.2010 on the protection of animals used for scientific purposes and the National Institutes of Health guide for the care and use of lab- 
oratory animals (NIH publications no. 8023, revised 1978). Animals had free access to a standard chow and water and were kept under a $12 \mathrm{~h}$ light/dark cycle. The room temperature and humidity were maintained automatically at about $22 \pm 2{ }^{\circ} \mathrm{C}$ and $60 \pm 5 \%$, respectively. After two weeks of adaptation, DM was induced by a single intraperitoneal injection of STZ at a dose of $60 \mathrm{mg}$ per $\mathrm{kg}$ bw. STZ was freshly prepared as solution in $10 \mathrm{mM}$ Na-citrate buffer ( $\mathrm{pH} 4.5)$ and injected into fasted overnight animals. Blood samples were obtained from the tail vein $72 \mathrm{~h}$ post-injection and the blood glucose level was measured using the glucose oxidase method (Filisit diagnostics kit, Ukraine). Rats having blood glucose concentration over $12 \mathrm{mmol} \mathrm{L}^{-1}$ were defined as diabetic and used for further experiments. The control group was selected among intact animals, which had a glucose concentration in the range of 3.7-5.0 $\mathrm{mmol} \mathrm{L}^{-1}$.

2.4.2 Experimental design. On the $10^{\text {th }}$ day after the induction of diabetes, DM rats were randomly separated into three groups of 8 animals each. The animals of the control group (healthy) and with DM (diabetic control) received $1 \mathrm{ml}$ of water daily during 14 days, intragastrically, while another set of diabetic animals was administered $1 \mathrm{ml}$ of aqueous solutions of extracts of red (RC) or yellow fruits of the cornelian cherry (YC) in the amount of $20 \mathrm{mg}$ per $\mathrm{kg}$ bw. The compounds were administered daily throughout the experimental period. The administration dose and duration were selected based on previous studies $^{21,22,26}$ and the content of main compounds, total polyphenols (YC: $326.75 \pm 7.12 \mathrm{mg}$ gallic acid equivalent per $\mathrm{g}$, RC: $375.30 \pm 4.04 \mathrm{mg}$ gallic acid equivalent per $\mathrm{g}$ ) and antioxidant activity (YC: $2.65 \pm 0.0301 \mu \mathrm{mol}$ trolox equivalent per g, RC: $2.83 \pm 0.01 \mu \mathrm{mol}$ trolox equivalent per $\mathrm{g}$ ) of cornelian cherry extracts from yellow and red fruits.

\subsection{Fasting glucose and OGTT}

The level of fasting glucose was measured using the glucose oxidase method (Filisit diagnostics kit, Ukraine). The blood was sampled from the tail vein in overnight fasted animals with free access to water. The oral glucose tolerance test (OGTT) was performed on the $13^{\text {th }}$ day of extract administration after $17 \mathrm{~h}$ of fasting. A baseline ( $0 \mathrm{~min}$ ) blood sample was collected from the tail vein in rats and then glucose solution was administered to all the experimental rats to inject $1 \mathrm{~g}$ per $\mathrm{kg}$ bw. Blood samples were then taken at 30, 60, 90, and $120 \mathrm{~min}$ after glucose loading. As the criterion which shows a general increase in glucose concentrations after glucose consumption, the index of the area under the glycemic curve $\left(\right.$ AUC $\left._{\text {glu }}\right)$ was measured. ${ }^{27}$

\subsection{Blood collection}

After 14 days of treatment, the rats were anesthetized using diethyl ether and euthanized by decapitation. Blood was collected into vials with heparin. Two millilitres of blood was centrifuged at $3000 \mathrm{rpm}$ to obtain plasma. Plasma was frozen and stored at $-20{ }^{\circ} \mathrm{C}$ for further measurements. Erythrocytes were washed three times with cold $\left(4^{\circ} \mathrm{C}\right)$ phosphate buffered saline (PBS, pH 7.4).

\subsection{Blood parameters}

2.7.1 Parameters related to erythrocytes. The count of erythrocytes in blood was performed manually using a counting chamber. Hemoglobin concentrations in whole blood were determined using the cyanmethemoglobin method, whereas mean cell hemoglobin $(\mathrm{MCH})$ was determined according to the study by Brodyak I. (2018). ${ }^{28}$ The glycated hemoglobin (HbA1c) content in erythrocytes was measured by the method based on the generation of 5-hydroxymethylfurfural from ketoamine after treatment with oxalic acid and its subsequent reaction with thiobarbituric acid to form a coloured adduct. Erythrocyte resistance to acid hemolysis was determined by the method described earlier. ${ }^{29}$ The following parameters were annotated: hemolysis duration, erythrocyte hemolysis peak, and ratio of mixed-age populations of erythrocytes (percentage).

2.7.2 Leukocyte related parameters. The total number of leukocytes in the blood was counted manually using a counting chamber. The differential leukocyte count was determined in painted smears of peripheral blood by the Romanovic Gimzia method. ${ }^{28}$ About 200 cells were analyzed per sample to quantify the percentage rate of individual forms of cells. ${ }^{28}$

\subsection{Characterization of carbonil oxidative stress in blood plasma}

The evaluation of oxidative stress in blood plasma was performed by measuring the content of products of lipid peroxidation, protein oxidation and carbonylation. Malondialdehyde (MDA) in blood plasma was assayed by using the thiobarbituric acid (TBA) and expressed as nmol per ml plasma with a molar absorption coefficient of $156000 \mathrm{M}^{-1} \mathrm{~cm}^{-1}$ at $532 \mathrm{~nm}^{30}$ The level of oxidative modified proteins (OMPs) was also determined. The method for determining the OMPs was based on spectrophotometric detection of the reaction of aldehyde and ketone groups of aliphatic amino acid residues with the 2,4-dinitrophenylhydrazine reagent which forms protein-conjugated 2,4-dinitrophenylhydrazones with a characteristic absorption spectrum at $370 \mathrm{~nm}\left(\mathrm{OMP}_{370}-\mathrm{OMPs}\right.$ of neutral characters) and at $430 \mathrm{~nm}\left(\mathrm{OMP}_{430}-\mathrm{OMPs}\right.$ of basic characters). ${ }^{31,32}$ The results of $\mathrm{OMP}_{370}$ were expressed as $\mu \mathrm{mol}$ of protein carbonyl groups per gram protein using a molar absorption coefficient of $22000 \mathrm{M}^{-1} \mathrm{~cm}^{-1}$, and the results of $\mathrm{OMP}_{430}$ were expressed as c.u. of protein carbonyl groups per gram protein. GSH as one of the predominantly low molecular weight plasma thiols was measured following the method of Beutler, which is based on the property of GSH to reduce 5,5'-dithiobis 2-nitrobenzoic acid (DTNB) forming a yellow coloured anionic product whose optical density is measured at $412 \mathrm{~nm} .{ }^{33}$ The concentration of GSH is expressed in $\mu$ mol per gram protein. The determination of AOPPs (i.e. some oxidation products with characteristic absorbance) was based on spectrophotometric detection according to Witko-Sarsat et al. modified by Kalousova et al. ${ }^{34,35}$ Two hundred microliters of blood plasma was diluted in a ratio of $1: 5$ with PBS, and $200 \mu \mathrm{l}$ of chloramine- $\mathrm{T}$ standard solutions ( 0 to $100 \mu \mathrm{mol} \mathrm{L}{ }^{-1}$ ) for calibration and $200 \mu \mathrm{l}$ of PBS as a blank were placed in the micro- 
titer plate. Afterwards, $10 \mu \mathrm{l}$ of $1.16 \mathrm{M}$ potassium iodide (KI) and $20 \mu \mathrm{l}$ of acetic acid were added. The absorbance of the reaction mixture was read at $340 \mathrm{~nm}$ against the blank. The concentration of AOPPs was expressed in chloramine units ( $\mu$ mol per gram protein). While the amount of blood plasma AGEs was determined according to method described by Putta et $a .^{1}$ plasma was diluted in 1:50 ratio with PBS

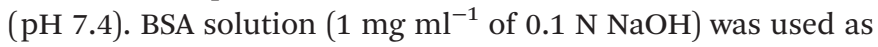
the standard and defined as one unit of fluorescence (AU). The level of AGEs in plasma was determined by measuring fluorescence at an excitation wavelength of $370 \mathrm{~nm}$ and an emission wavelength of $440 \mathrm{~nm} .{ }^{1}$ The fluorescence intensity of the samples was expressed as AU per mg protein.

\subsection{Statistical analysis}

Values are expressed as mean \pm standard error of the mean ( $\mathrm{m} \pm \mathrm{SEM})$. Data were analyzed statistically by the two-way analysis of variance ANOVA (GraphPad software v5.0; Prism).
Differences between the groups were considered statistically significant at $P<0.05$.

\section{Results}

\subsection{The chemical composition of cornelian cherry extracts}

The results of qualitative and quantitative identification of the compounds of cornelian cherry extracts are presented in Table 1 . The compounds were identified by their retention times, elution order, and spectra of the individual peaks (UV/ Vis, MS, MS/MS), and by comparison with literature data. In our research, we determined 29 main compounds from two groups: 8 iridoids and 21 phenolic compounds. Among the eight iridoids, three isomers of loganic acid, sweroside, loganin, and secoxyloganin and two isomers of cornuside were identified. These eight iridoids were analyzed in both positive and negative modes before and after fragmentation.

Table 1 Identification and the content (mg per $100 \mathrm{~g} \mathrm{dw}$ ) of main compounds of cornelian cherry extracts from yellow (YC) and red (RC) fruits by UPLC-ESI-qTOF-MS/MS and HPLC-PDA

\begin{tabular}{|c|c|c|c|c|c|c|c|}
\hline $\begin{array}{l}\text { Peak } \\
\text { no. }\end{array}$ & $t_{R}(\min )$ & Compound & $\begin{array}{l}\text { UV } \lambda_{\max } \\
(\mathrm{nm})\end{array}$ & {$[\mathrm{M}-\mathrm{H}]^{-} /[\mathrm{M}+\mathrm{H}]^{+}(m / z)$} & $\begin{array}{l}\text { Other ions } \\
(\mathrm{m} / \mathrm{z})\end{array}$ & \multicolumn{2}{|c|}{ Content (mg per $100 \mathrm{~g} \mathrm{dw}$ ) } \\
\hline \multicolumn{8}{|c|}{ Iridoids } \\
\hline 2 & 5.2 & Loganic acid isomer 1 & 245 & $375(377+)$ & $213(215+)$ & $1266.46 \pm 13.8$ & $572.34 \pm 7.97$ \\
\hline 3 & 6.1 & Loganic acid isomer 2 & 245 & $375(377+)$ & $213(215+)$ & $520.15 \pm 1.05$ & $468.68 \pm 5.17$ \\
\hline 4 & 8.7 & Sweroside & 245 & $403[\mathrm{M}-\mathrm{H}+46]^{-}(359+)$ & $195(197+)$ & $609.88 \pm 6.99$ & $548.12 \pm 3.62$ \\
\hline 7 & 16.1 & Cornuside 1 & $245 / 273$ & $541(543+)$ & 169 & $2731.7 \pm 29.4$ & $1930.2 \pm 10.2$ \\
\hline \multirow[t]{2}{*}{8} & 16.5 & Cornuside 2 & $245 / 273$ & $541(543+)$ & 169 & $78.90 \pm 2.50$ & $64.22 \pm 1.70$ \\
\hline & & Total & & & & 20303.75 & 14068.98 \\
\hline \multicolumn{8}{|c|}{ Anthocyanins } \\
\hline 9 & 6.3 & Delphinidin 3-O-galactoside & 524 & $463+$ & $303+$ & nd & $46.5 \pm 4.94$ \\
\hline 10 & 7.6 & Cyanidin 3-O-galactoside & 515 & $449+$ & $287+$ & nd & $759.2 \pm 0.94$ \\
\hline 11 & 8.3 & Cyanidin 3-O-robinobioside & 516 & $595+$ & $287+$ & nd & $223.2 \pm 2.34$ \\
\hline & & Total & & & & & 3066.80 \\
\hline \multicolumn{8}{|c|}{ Phenolic acids } \\
\hline 16 & 4.1 & Caffeoylhexoside 1 & 326 & 341 & 179 & $228.56 \pm 2.41$ & $123.06 \pm 2.45$ \\
\hline 17 & 4.6 & $p$-Coumaroilquinic acid 1 & 316 & 337 & 163 & $92.66 \pm 0.43$ & $51.09 \pm 0.30$ \\
\hline 18 & 5.8 & Caffeoylquinic acid 1 & 324 & 353 & 191 & $834.71 \pm 13.52$ & $585.53 \pm 3.26$ \\
\hline 19 & 5.8 & Caffeic acid & 324 & 179 & - & $116.17 \pm 0.86$ & $91.71 \pm 0.44$ \\
\hline 20 & 7.6 & Caffeoylquinic acid 2 & 323 & 353 & 191 & $14.48 \pm 1.20$ & Trace \\
\hline 21 & 7.9 & $p$-Coumaric acid & 309 & 163 & - & $74.20 \pm 1.73$ & $8.58 \pm 0.20$ \\
\hline 22 & 8.3 & $p$-Coumaroilquinic acid 2 & 313 & 337 & $191 / 163$ & $702.02 \pm 12.77$ & $301.86 \pm 2.56$ \\
\hline 23 & 10.0 & $p$-Coumaroilquinic acid 3 & 312 & 337 & $191 / 163$ & $48.22 \pm 2.24$ & $21.66 \pm 0.17$ \\
\hline \multirow[t]{2}{*}{24} & 12.3 & Ellagic acid & $254 / 362$ & 301 & - & $46.15 \pm 3.44$ & $102.03 \pm 1.10$ \\
\hline & & Total & & & & 2157.17 & 1285.52 \\
\hline \multicolumn{8}{|c|}{ Flavonols } \\
\hline 25 & 12.9 & Quercetin 3-O-galactoside & 353 & 463 & 301 & $39.84 \pm 0.45$ & $55.32 \pm 0.38$ \\
\hline
\end{tabular}

nd, not detected. 
Compounds 1, 2, and 3 were found to be isomers of loganic acid. They had a pseudomolecular ion at $m / z 375[\mathrm{M}-\mathrm{H}]^{-}$and a fragment ion at $213[\mathrm{M}-\mathrm{H}-162]^{-}$. Compounds 4 and 5 occurred in the form of adducts at $m / z 403[\mathrm{M}-\mathrm{H}+46]^{-}$and $435[\mathrm{M}-\mathrm{H}+46]^{-}$respectively rather than in the form of molecular ions at $\mathrm{m} / \mathrm{z} 357$ and 389, respectively. These compounds were identified as sweroside and loganin, respectively. Compound 6 gave $[\mathrm{M}-\mathrm{H}]^{-}$ions at $m / z 403$ and $[\mathrm{M}+\mathrm{H}]^{+}$and fragment ions at $\mathrm{m} / \mathrm{z} 371$ and 233 in negative mode. It was identified as secoxyloganin. Compounds 7 and 8 exhibited pseudomolecular ions at $m / z 541[\mathrm{M}-\mathrm{H}]^{-}$and fragment ions at $m / z$ 169. Compounds 7 and 8 were tentatively identified as isomers of cornuside. The identification results for four of the eight identified iridoids in the cornelian cherry fruits were previously described by Kucharska (2012), Deng et al. (2013), and Kucharska et al. (2015), whereas the two isomers of loganic acid, secoxyloganin and cornuside 2 were identified in purified extracts of the cornelian cherry fruit for the first time. ${ }^{23,36,37}$

The phenolic compounds can be classified into three groups: anthocyanins, phenolic acids, and flavonols. Anthocyanins were identified exclusively in red cornelian cherry extracts. These compounds were analyzed in positive modes before and after fragmentation. Among the seven anthocyanins, there were three monoglucosides (delphinidin 3-O-galactoside with $[\mathrm{M}+\mathrm{H}]^{+}$at $m / z 463$ and $[\mathrm{M}+\mathrm{H}-162]^{+}$at $\mathrm{m} / \mathrm{z}$ 303; cyanidin 3-O-galactoside with $[\mathrm{M}+\mathrm{H}]^{+}$at $\mathrm{m} / \mathrm{z} 449$ and $[\mathrm{M}+\mathrm{H}-162]^{+}$at $\mathrm{m} / z$ 287, pelargonidin 3-O-galactoside with $[\mathrm{M}+\mathrm{H}]^{+}$at $m / z 433$ and $[\mathrm{M}+\mathrm{H}-162]^{+}$at $\left.m / z 271\right)$, two diglucosides (cyanidin 3-O-robinobioside with $[\mathrm{M}+\mathrm{H}]^{+}$at $m / z 595$ and $[\mathrm{M}+\mathrm{H}-308]^{+}$at $m / z$ 287; pelargonidin 3-O-robinobioside with $[\mathrm{M}+\mathrm{H}]^{+}$at $m / z 579$ and $[\mathrm{M}+\mathrm{H}-308]^{+}$at $m / z 271$ ), and two aglicons (cyanidin with $[\mathrm{M}+\mathrm{H}]^{+}$at $m / z 287$, pelargonidin with $[\mathrm{M}+\mathrm{H}]^{+}$at $\left.m / z 271\right)$. Five anthocyanin glycosides had been previously identified in red cornelian cherry fruits. ${ }^{36}$ Anthocyanin aglycans are formed after the detachment of sugars as a result of hydrolysis under the influence of various factors. In this case, they were created at the stage of obtaining and purifying the fruit extract.

Eight hydroxycinnamic acids and one hydroxybenzoic acid were determined among phenolic acids. In this first group, $p$-coumaric acid with $[\mathrm{M}-\mathrm{H}]^{-}$at $m / z 163$ and three isomers of $p$-coumaroylquinic acid with $[\mathrm{M}-\mathrm{H}]^{-}$at $m / z 337$ and fragment ions at $m / z 191$ and 163 were identified. In addition, a pseudomolecular ion was identified at $\mathrm{m} / \mathrm{z} 179$ corresponding to caffeic acid, two pseudomolecular ions - at $\mathrm{m} / \mathrm{z} 353$ and a fragment ion - at 191 corresponding to two isomers of caffeoylquinic acid, and one pseudomolecular ion - at $\mathrm{m} / \mathrm{z} 341$ corresponding to caffeoylhexoside. Compound 24 was identified as ellagic acid with a pseudomolecular ion at $m / z 301[\mathrm{M}-\mathrm{H}]^{-}$ and with the UV spectrum at 254 and $362 \mathrm{~nm}$.

Among the flavonols, three quercetin derivatives were identified in both red and yellow cornelian cherry extracts and two kaempferol derivatives were identified only in the red cornelian cherry extract. These compounds were analyzed in negative modes before and after fragmentation. Compounds 25, 26, and 27 exhibited pseudomolecular ions at $m / z 463,477$, and 463 respectively with the same fragment ion at $m / z 301$, which corresponded to the molecular ion of the quercetin moiety, after the loss of a galactose, glucuronide, and glucose respectively. Compounds 28 and 29 had pseudomolecular ions at $\mathrm{m} / \mathrm{z} 447$ and 461 respectively and the same fragment ion at $\mathrm{m} / \mathrm{z} 285$ which corresponded to the molecular ion of the kaempferol moiety, after the loss of the galactose and glucuronide, respectively.

Pawlowska et al. (2010) identified eight compounds from the flavonol group in the fruits of Cornus mas $\mathrm{L}^{38}{ }^{38}$ The identification of quercetin 3-O-galactoside, quercetin 3-O-glucuronide, quercetin 3-O-glucoside and kaempferol 3-O-galactoside was qualitatively consistent with previous reports. ${ }^{37}$ In their research, those authors identified three more derivatives of quercetin and one derivative of aromadendrin, which have not been identified in our research. This may be due to many reasons, e.g. different procedures for preparing samples for determinations or different sensitivity of analytical methods or difference in fruit varieties. However, kaempferol 3-O-glucuronide has been detected in our extract from red fruits for the first time.

The amount of total iridoids varied widely in extracts of yellow and red fruits of Cornus mas L. and ranged from $20.3 \mathrm{~g}$ per $100 \mathrm{~g}$ dw to $14.1 \mathrm{~g}$ per $100 \mathrm{~g}$ dw, respectively (Table 1). Anthocyanins were $30.1 \mathrm{~g}$ per $100 \mathrm{~g}$ dw in the red fruit extract. In the analyzed extracts, we have determined from 28 to 41 times more iridoids and 9 times more anthocyanins than in unpurified extracts of the best cultivar cornelian cherry. ${ }^{36}$ Due to the fact that the studied extracts have a similar component composition relative to the percentages of iridoids (YC: $88.2 \%$, RC: $73.5 \%$ ), but differ in the content of anthocyanins (YC: $0 \%$ vs. RC: $16 \%)$, the extracts were administered to animals with diabetes to evaluate which extract contains the more effective components - iridoids or a mixture of iridoids with anthocyanins.

\subsection{Effect of red and yellow cornelian cherry extracts on weight gain and glucose related parameters}

The body weight of animals increased throughout the experiment. The weight gain of the control animals was 33\%, while for diabetic ones $-9 \%$. The administration of extracts of red and yellow fruits of cornelian cherries led to a significant increase in body weight gain in the animals with diabetes (Table 2).

Glucose concentration in blood was measured on $10^{\text {th }}, 17^{\text {th }}$ and $24^{\text {th }}$ days (Fig. 1A). Blood glucose was about $4.5 \pm$ $0.2 \mathrm{mmol} \mathrm{L}^{-1}$ in the control animals during the experiment. It increased to 13.6 to $15.4 \mathrm{mmol} \mathrm{L}^{-1}$ in the animals injected with STZ (Fig. 1A). The diet supplementation with the extract of red and yellow fruits of Cornus mas L. significantly decreased the concentration of glucose in diabetic animals 1.7- and 1.3 -fold on the $17^{\text {th }}$ day of the experiment (seventh day of oral administration), respectively (Fig. 1A). According to the data on the last day of the experiment, the administration of extracts of red and yellow fruits of Cornus mas L. observed a significant lowering of blood glucose concentration as compared to the STZ-treated group (Fig. 1B). In diabetic animals 
Table 2 Effect of cornelian cherry extracts on the body weight of diabetic rats after 14 days of administration

\begin{tabular}{|c|c|c|c|c|}
\hline \multirow[b]{2}{*}{ Groups } & \multicolumn{4}{|l|}{ Body weight } \\
\hline & Weight at $1^{\text {st }}$ day of administration, $g$ & Weight at $14^{\text {th }}$ day of administration, $g$ & Gain, $g$ per 14 days & Gain, \% \\
\hline Control & $139 \pm 2$ & $185 \pm 4$ & $45.6 \pm 1.4^{b}$ & $33 \pm 3^{b}$ \\
\hline $\mathrm{DM}$ & $142 \pm 1$ & $127 \pm 6$ & $-15.1 \pm 1.1^{a}$ & $-9 \pm 2^{a}$ \\
\hline $\mathrm{DM}+\mathrm{RC}$ & $147 \pm 1$ & $158 \pm 4$ & $10.7 \pm 1.9^{a, b}$ & $7 \pm 3^{a, b}$ \\
\hline $\mathrm{DM}+\mathrm{YC}$ & $137 \pm 1$ & $145 \pm 4$ & $7.3 \pm 1.3^{a, b}$ & $5 \pm 2^{a, b}$ \\
\hline
\end{tabular}

${ }^{a} P<0.05$ as compared to the control group. ${ }^{b} P<0.05$ as compared to the diabetes group. DM - diabetes mellitus; RC and YC - extracts of red and yellow cornelian cherry fruits, respectively.
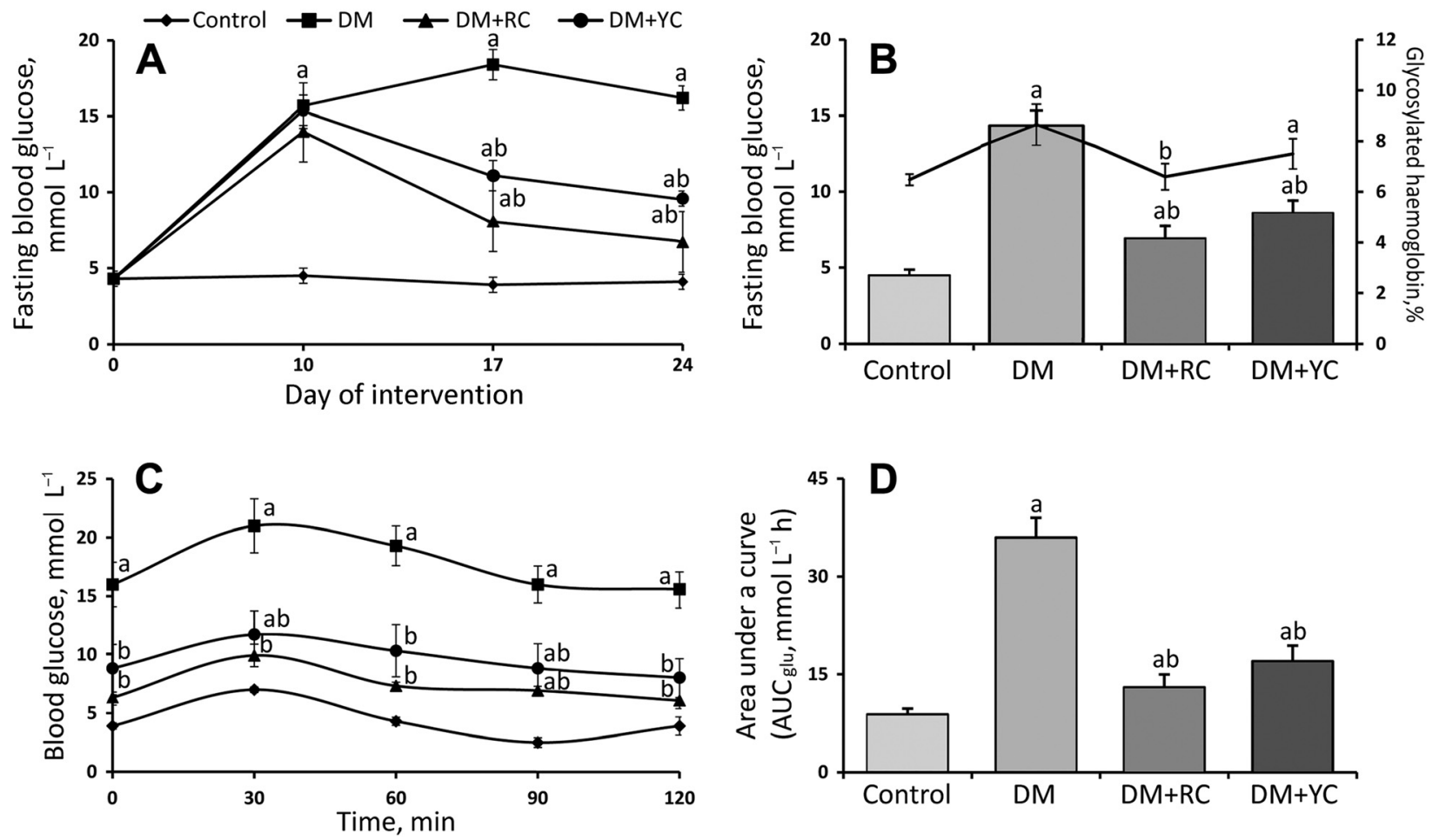

Fig. 1 Glucose related parameters under administration of cornelian cherry extracts. The dynamics of blood glucose concentration, $\mathrm{mmol}^{-1}$ (A); fasting blood glucose, $\mathrm{mmol} \mathrm{L}^{-1}$, and glycated hemoglobin, \% of total hemoglobin (B); oral glucose tolerance test, $\mathrm{mmol}^{-1}$ blood glucose levels (C) and the area under the curve after glucose load of rats, $\mathrm{mmol} \mathrm{L}^{-1} \mathrm{~h}^{-1}$ (D). The results are shown as the mean $\pm \mathrm{SEM}$. Designations: $a-P<0.05$ compared to the control group; $b-P<0.05$ compared to the DM group.

treated with the extract of red and yellow fruits of Cornus mas L., the blood glucose concentration lowered to about 7.1 and $8.6 \mathrm{mmol} \mathrm{L}^{-1}$, respectively. Glycated hemoglobin was significantly increased in diabetic rats as compared to the control group and decreased after treatment with the extract of red fruits of the cornelian cherry (Fig. 1B). No significant changes in the level of glycated hemoglobin were found after the administration of the extract of yellow fruits of the cornelian cherry (Fig. 1B). The results indicate that Cornus mas L. induces hypoglycemic effects in the STZ-diabetic rats.

Oral glucose tolerance tests were used to determine the acute effect of extracts of red and yellow fruits of Cornus mas L. on diabetic rats (Fig. 1C). In the control rats, blood glucose concentration peaked on the $30^{\text {th }}$ min after oral glucose loading and then decreased to the baseline on the $60^{\text {th }}$ min. However, blood glucose concentrations were still higher in diabetic rats in the $60^{\text {th }}$ min after glucose ingestion. After the administration of red and yellow cornelian cherry extracts, blood glucose levels peaked on the $30 \mathrm{~min}$ and then slowly decreased to the fasting level. The differences between cornelian cherry-treated groups and the diabetic group on the $120^{\text {th }}$ min were statistically significant. The glycemic response of all the groups was expressed as the $\mathrm{AUC}_{\text {glc }}$ (Fig. 1D). The values of $\mathrm{AUC}_{\text {glc }}$ were significantly lower in the cornelian cherry-treated diabetic rats than in the diabetic group 3.0- and 2.1-fold, respectively. Thus the cornelian cherry extracts significantly affected the fasting blood glucose and postprandial glucose level. 


\subsection{Effect of cornelian cherry extracts on the content of} carbonyl-oxidative stress metabolites in rats' blood plasma

In rats with STZ-induced DM, the plasma GSH level decreased significantly by $28 \%$ (Fig. 2A). The administration of extracts of red and yellow cornelian cherries to animals with DM caused an increase in this indicator, compared to the nontreated diabetic group.

As shown in Fig. 2B, the plasma TBA-reactive substance (TBARS) level was increased significantly about $75 \%$ in the diabetic group compared to the control rats. After treatment with cornelian cherry extracts, the TBA-reactive substance level was significantly lowered only by red fruits of Cornus mas L. about $42 \%$ compared to the diabetic rats.

The attack of proteins by reactive oxygen species modifies amino acid residues generating carbonyl moieties under conditions of oxidative stress. It was found (Fig. 2C and D) that the level of $\mathrm{OMP}_{370}$ and $\mathrm{OMP}_{430}$ increased in rats' blood plasma under diabetic conditions compared to the control group (57 and $32 \%$, respectively). The administration of the extract of red fruits of Cornus mas L. to animals with DM caused a decrease in the level of protein carbonyl groups with neutral character about 1.4-fold (Fig. 2C). After the administration of the extract of yellow fruits of Cornus mas L. a significant decrease of the level of protein carbonyl groups with a basic character was shown compared to the diabetic group.
The plasma AGE level was increased significantly about 1.5fold in the diabetic group compared to the control rats (Fig. 3A). After treatment with cornelian cherry extracts of red and yellow fruits, the AGE level was significantly lowered compared to DM values. Another marker of oxidative stress and subsequent damage of proteins in conditions of DM is the AOPPs. We observed an increase in the AOPP level under DM about 1.9-fold compared with the control group (Fig. 3B). In contrast, the administration of extracts of red and yellow cornelian cherries to animals with DM caused a decrease in this indicator (1.6- and 3.2-fold respectively), being much more effective in the yellow cornelian cherry-treated group.

\subsection{Effect of cornelian cherry extracts on leukocytes and erythrocyte related parameters}

No changes of the total number of leukocytes in diabetic rats and the introduction of red and yellow cornelian cherry extracts compared to the control group were shown (Table 3). In animals with DM, the ratio of segmented neutrophils and lymphocytes has changed (Table 3), but the total number of banded neutrophils, eosinophils and monocytes did not differ from those in the control group. The treatment of diabetic animals with cornelian cherry extracts led to normalization of the segmented neutrophils, monocytes and peripheral blood lymphocyte percentage ratio (Table 3 ). Such changes reflect the
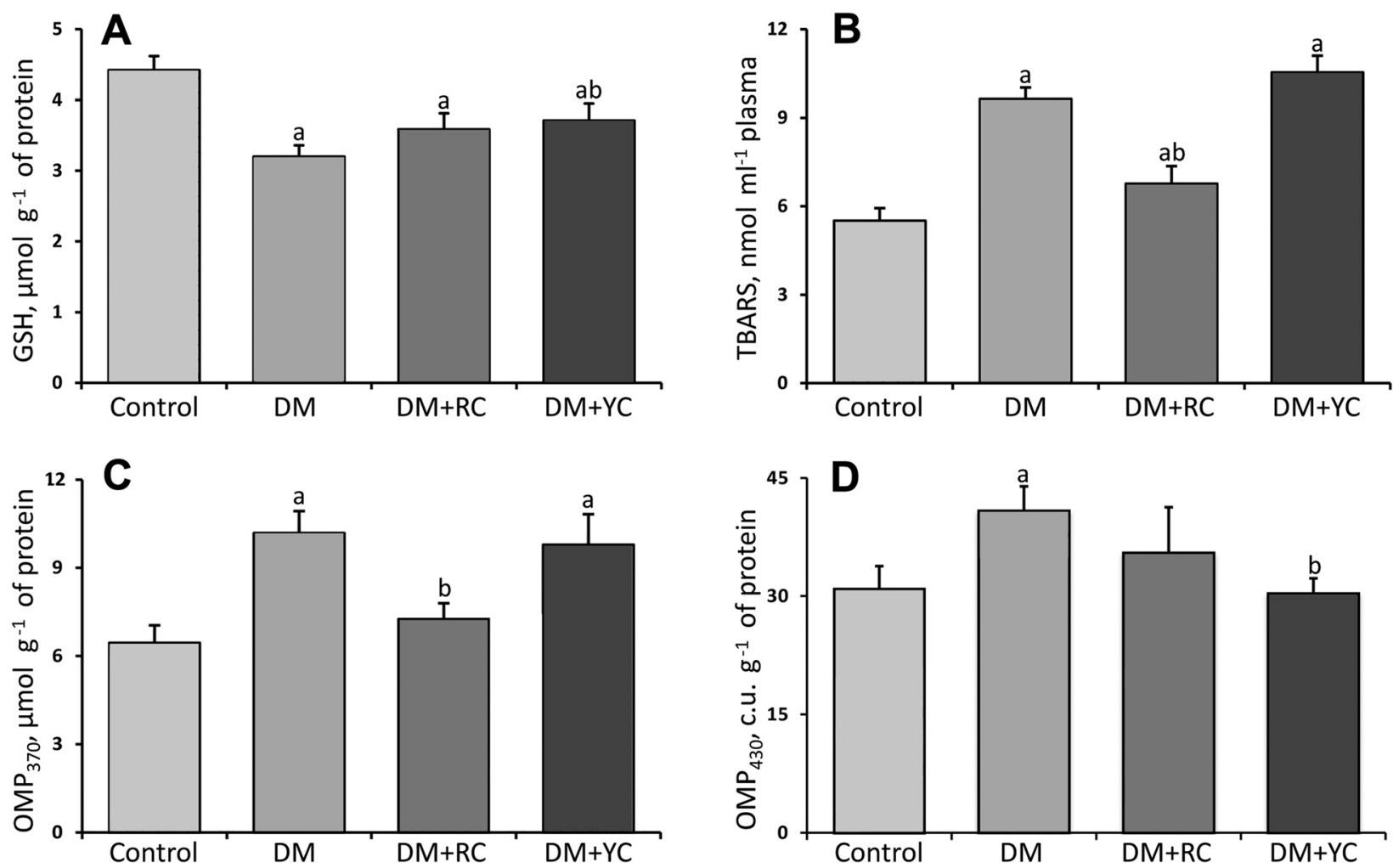

Fig. 2 The content of reduced glutathione, $\mu \mathrm{mol} \mathrm{g} \mathrm{g}^{-1}(\mathrm{~A})$, TBA-reactive substances, $\mathrm{nmol} \mathrm{ml}^{-1}(\mathrm{~B})$, oxidative modifications of proteins (OMP) of neutral, $\mu \mathrm{mol} \mathrm{g}^{-1}$ (C) and basic, c.u. $\mathrm{g}^{-1}$ (D) character rats' blood plasma under diabetes mellitus (DM), after treatment with red (RC) and yellow cornelian (YC) cherry extracts. The results are shown as the mean \pm SEM. Designations: $a-P<0.05$ compared to the control group; $b-P<0.05$ compared to the DM group. 

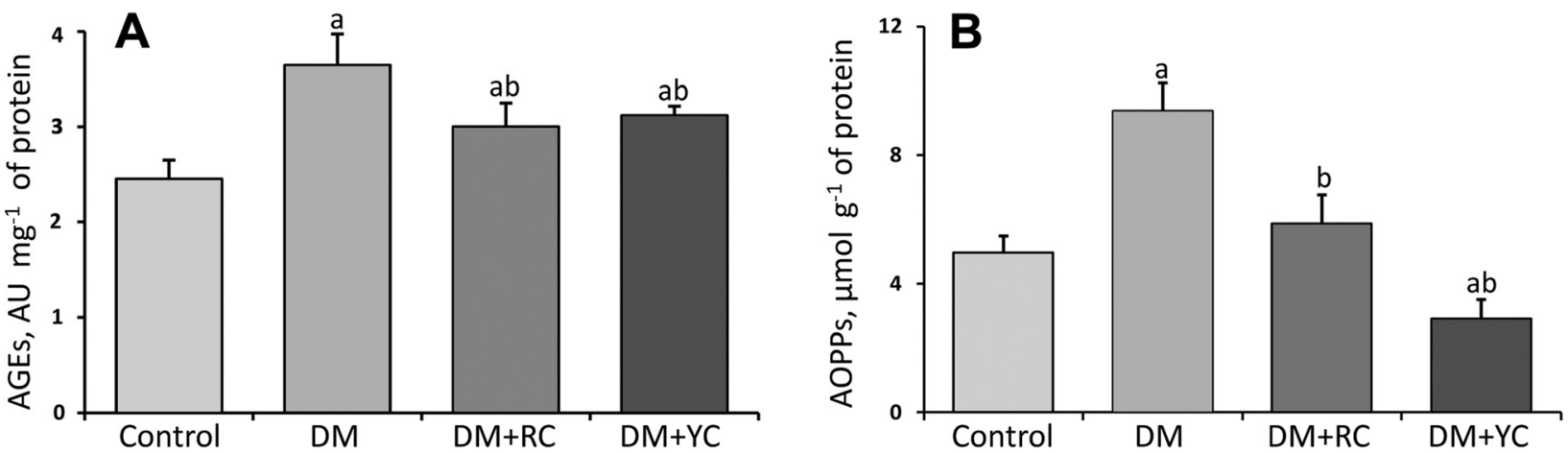

Fig. 3 The effect of Cornus mas L. extracts on the content of advanced glycation end products, $\mathrm{AU} \mathrm{mg}^{-1}$ (A) and advanced oxidation protein products, $\mu \mathrm{mol} \mathrm{g}^{-1}(\mathrm{~B})$ in rats' blood plasma under $\mathrm{DM}$. The results are shown as the mean $\pm \mathrm{SEM}$. Designations: a $-P<0.05$ compared to the control group; $\mathrm{b}-P<0.05$ compared to the DM group.

Table 3 Effect of red and yellow cornelian cherry extracts on indicators of the differential leukocyte count, number of red blood cells and hemoglobin content in diabetic rats

\begin{tabular}{|c|c|c|c|c|}
\hline \multirow[b]{2}{*}{ Parameters } & \multicolumn{4}{|l|}{ Groups } \\
\hline & Control & $\mathrm{DM}$ & $\mathrm{DM}+\mathrm{RC}$ & $\mathrm{DM}+\mathrm{YC}$ \\
\hline Number of red blood cells, $10^{6} \mu \mathrm{L}^{-1}$ & $5.9 \pm 0.6$ & $5.8 \pm 0.6$ & $6.1 \pm 0.3$ & $5.2 \pm 0.4$ \\
\hline Hemoglobin content, $\mathrm{g} \%$ & $12.3 \pm 1.4$ & $10.1 \pm 0.7$ & $10.0 \pm 0.8$ & $10.6 \pm 0.9$ \\
\hline Mean cell hemoglobin, pg & $21.6 \pm 1.2$ & $17.4 \pm 1.1^{a}$ & $16.5 \pm 0.7^{a}$ & $20.5 \pm 0.6^{b}$ \\
\hline Leukocytes, $10^{3} \mu \mathrm{L}^{-1}$ & $11.2 \pm 0.5$ & $13.0 \pm 1.1$ & $12.0 \pm 1.5$ & $11.3 \pm 2.7$ \\
\hline Banded neutrophilis, \% & $1.16 \pm 0.21$ & $1.34 \pm 0.42$ & $1.40 \pm 0.39$ & $1.40 \pm 0.45$ \\
\hline Monocytes, \% & $0.38 \pm 0.23$ & $0.41 \pm 0.25$ & $1.04 \pm 0.03$ & $1.06 \pm 0.25$ \\
\hline Basophils, \% & 0 & 0 & 0 & 0 \\
\hline Eosinophils, \% & $1.15 \pm 0.35$ & $0.96 \pm 0.29$ & $2.08 \pm 0.05$ & $0.50 \pm 0.04$ \\
\hline
\end{tabular}

${ }^{a} P<0.05$ compared to the control group. ${ }^{b} P<0.05$ compared to the DM group.

positive effect of the Cornus mas L. extract on hematological parameters and functioning of immune defence under DM.

The total number of erythrocytes and hemoglobin concentration did not undergo significant changes under diabetes mellitus in comparison with the control; however, the $\mathrm{MCH}$ was significantly decreased by $19.4 \%$ (Table 3 ). After the treatment of diabetic rats with the extract of red and yellow cornelian cherries, the total number of erythrocytes and hemoglobin concentration did not change, but the $\mathrm{MCH}$ increased to values of the control group in yellow fruit extract-treated animals (Table 3).

Additionally, we investigated the distribution of erythrocytes according to their resistance to the acid hemolytic agent. The erythrogram in the control group of animals is characterized by a rapid rise of the curve after the $2^{\text {nd }}$ min with a maximum on the $4^{\text {th }}$ min and a gradual slow decrease to zero on the $9.5^{\text {th }}$ min (Fig. $4 \mathrm{~A}$ and B). The curve can be divided into three segments (Fig. 4C): the segment from 1.5 to $3.0 \mathrm{~min}-$ reticulocytes and RBCs with reduced resistance aged over 40 days, the segment from 3.5 to $4.5 \mathrm{~min}$ - functional mature RBCs with moderate resistance aged 20-40 days, the segment from 5.0 to $7.5 \mathrm{~min}$ - young erythrocytes with increased resistance aged up to 20 days. Under conditions of DM, we found reduced resistance of $\mathrm{RBC}$ to the action of the acid hemolytic agent. This manifested in the growth of the lysed RBC number at the peak of hemolysis (Fig. 4A) and reduction of process duration to the $7.0^{\text {th }}$ min (Fig. 4B). After the administration of red and yellow cornelian cherry extracts, the hemolysis peak shifted to the right and the hemolysis duration was increased (Fig. 4B). The results indicate the increase of erythrocyte resistance to the acid hemolysis agent (Fig. 4C).

\section{Discussion}

Disturbance of glucose metabolism in conditions of diabetes is accompanied by changes in different body organs, including blood, which greatly initiates the development of diabetic complications. The process of protein glycosylation and disruption of the antioxidant defence system in blood cells influence the organism state under DM. ${ }^{9,12}$ Possible remedies to reduce diabetes-induced abnormalities have been searched. Currently available drugs for diabetes have a number of limitations such as adverse effects and high rates of secondary failure. ${ }^{39}$ The situation has led to the search for alternative therapies made from natural products that have low or no side effects and 

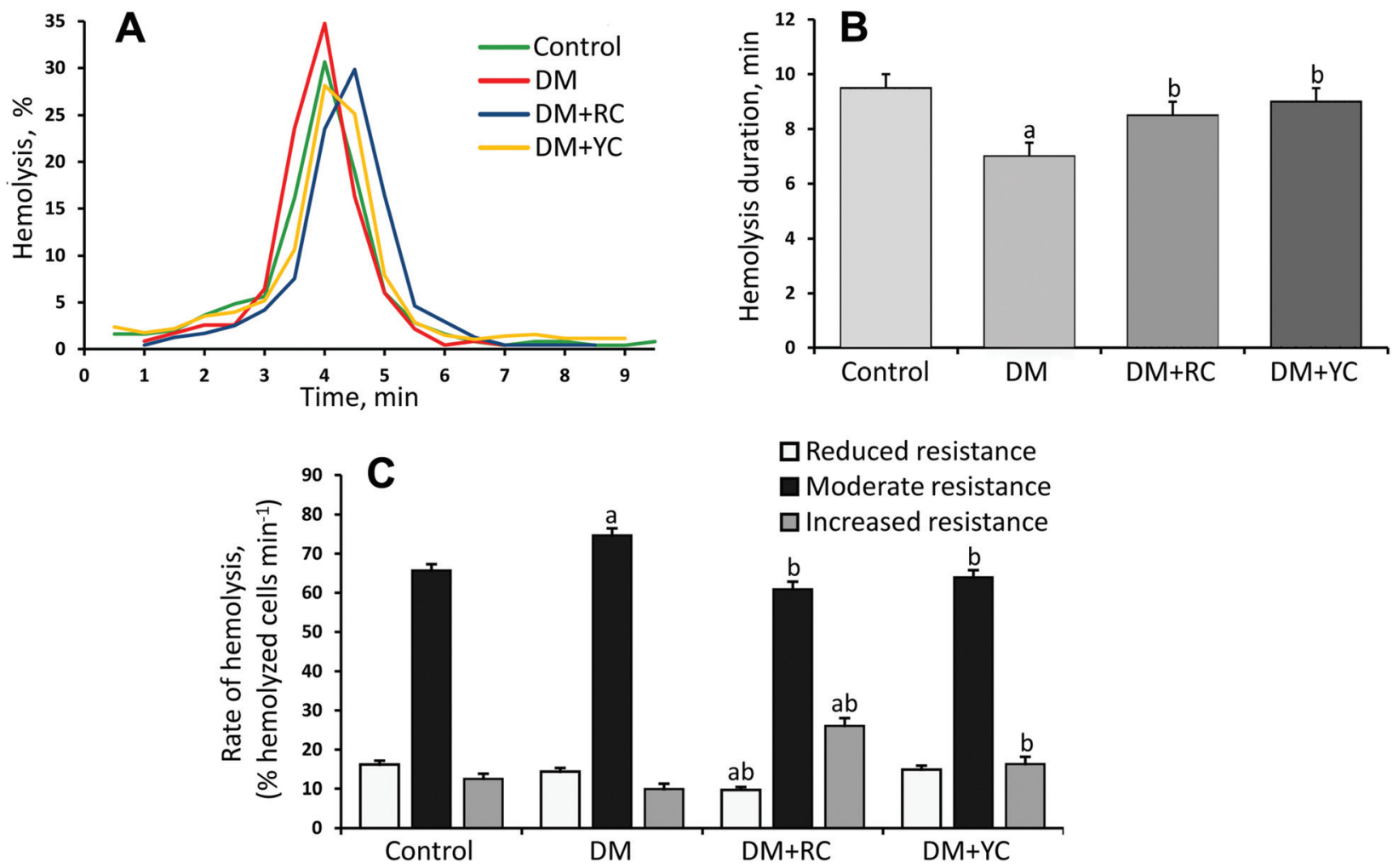

Fig. 4 Typical erythrograms (A), hemolysis duration, min. (B) and the ratio of mixed-age populations of erythrocytes, \% (C) in control, under the conditions of DM and the introduction of red and yellow cornelian cherry extracts. The results are shown as the mean + SEM. Designations: a $-P<$ 0.05 compared to the control group; $b-P<0.05$ compared to the DM group.

multi-target actions. ${ }^{40}$ At present, the area warrants more attention. Medicinal plants play a major role in the introduction of new therapeutic agents and have received much attention as the sources of biologically active substances. ${ }^{15}$

Corni Fructus (Cornus officinalis Sieb. et Zucc.) is one of the components of Rokumi-gan, Hachimi-jio-gan, and Goshajinki-gan, prescribed for diabetes treatment. Some studies have shown that Corni Fructus contains several active components which protect against diabetes and its complications and exerts multifaceted effects. ${ }^{20}$ Morroniside, one of the major iridoid glycoside components isolated from Corni Fructus, showed protective effects against diabetic renal damage by inhibiting hyperglycemia and oxidative stress. ${ }^{41}$ 7-O-Galloyl-Dsedoheptulose, a major low-molecular weight polyphenol of Corni Fructus, inhibited diabetic oxidative stress and AGE formation. ${ }^{42}$ Instead, the main compounds of Cornus mas L. are loganic acid (1) and cornuside 1 (7) in extracts of red and yellow fruits and additionally pelargonidin 3-O-galactoside (12) in the extract of red fruits. The antioxidant properties of Cornus mas L. fruits have been shown in several other studies using different assay methods. ${ }^{21,22}$ In this study, we have investigated the antidiabetic effect of the extract of Cornus mas L. fruits in rats with STZ-induced DM.

STZ-induced DM is characterized by a severe loss in body weight, which might be the result of protein wasting since carbohydrates are not available as an energy source. ${ }^{7,15}$ In this experiment, diabetic rats showed a significant decrease in body weight gain compared with control rats during 14 days of the experimental period. This weight retardation can be related to the reduction of glucose uptake caused by the lack of insulin after STZ injection. The extract of the red and yellow cornelian cherry reduced the decline in body weight in diabetic rats. The administration of extracts of the cornelian cherry may initiate a glucose uptake by peripheral tissues and thus improves the metabolism of glucose as one of the main sources of energy.

Also, in this study we have investigated a hypoglycemic effect of extracts of Cornus mas L. under DM in rats. Postprandial increases of blood glucose in rats with DM may depend on several factors. ${ }^{43}$ The factors include the rate of gastric emptying, pancreatic enzyme secretion, intestinal mucosal enzyme activity, intestinal absorptive capacity, and intestinal motility. The administration of the extract of red and yellow cornelian cherries leads to a decrease in blood glucose concentrations and the glycated hemoglobin content compared with non-treated diabetic rats. The OGTT was employed to assess glucose metabolism and it showed an improved glucose tolerance in extract-treated rats. According to OGTT data we suggest that the extract of Cornus mas L. fruits can improve the sensitivity of $\beta$-cell insulin receptors in the STZinduced diabetic rats. Nevertheless, further research is needed. The mechanisms to lower blood glucose are: stimulation of pancreatic islet $\beta$-cells to release insulin, inhibition of 
hormone release which elevates blood glucose, an increase the number, affinity or sensitivity of insulin receptors, and stimulation of glucose by using peripheral organs. ${ }^{44}$ We hypothesize that it may be due to the ability of the extracts to increase the utilization of glucose by peripheral tissues under conditions of hypoinsulinemia.

Anthocyanins are one of the major components isolated from Cornus mas L. red fruits. Anthocyanins decrease the blood glucose level and peripheral insulin resistance both in animal models of diabetes and human cross-sectional study ${ }^{45-47}$ It was shown that procyanidins derived from grape seeds stimulate glucose uptake and glucose transporter-4 translocation to the plasma membrane in insulin-sensitive cell lines. ${ }^{48}$ Also proanthocyanidins can inhibit intestinal glucose absorption. Park et al. reported that the Corni Fructus extract has the potential to suppress postprandial hyperglycemia by $\alpha$-glucosidase inhibition as one of its antidiabetic effects. Its effect was exerted by an active fraction containing polymeric proanthocyanidins. According to this investigation, polymeric proanthocyanidins from Corni Fructus at a dose of $20 \mathrm{mg}$ per $\mathrm{kg}$ bw significantly inhibited an increase in blood glucose levels after sucrose loading. ${ }^{20}$

The cornelian cherry extract-mediated inhibition of $\alpha$-glucosidase may be a possible mechanism for decreasing the blood glucose level, as shown in other studies. ${ }^{49} \alpha$-Glucosidase is an enteric enzyme, which hydrolyzes polysaccharides into monosaccharides with followed absorption at the intestinal mucosa. ${ }^{50}$ The inhibition of $\alpha$-glucosidase leads to the reduction of glucose entering in the bloodstream. We suggest that compounds of Cornus mas L. fruits probably interfere with the transit, digestion or absorption of sugars in the small intestine, resulting in a decrease of the blood glucose level.

Diabetes is an endocrine disease that causes a metabolic disorder affecting carbohydrate, fat and protein metabolism complicated by multiorgan deterioration in the latter stages of the illness. ${ }^{15}$ Under conditions of diabetes, a large amount of glucose accumulates and is intensively utilized by insulin-free tissue cells via glycolysis and in the Krebs cycle. As a result, the work of the mitochondria electron transport chain is intensified with the excess formation of superoxide anion radicals. Superoxide anions can disproportionate into other highly reactive radicals, which cause modifications of proteins and lipids. ${ }^{51,52}$ Under physiological conditions, the active metabolites of oxygen are neutralized by various components of the antioxidant defence system. The GSH is a low-molecular antioxidant and one of the important indicators within the cell that determines the level of oxidative stress. NADPH is one of the compounds that affect the level of GSH and the major element for the functioning of glutathione system enzymes. The activation of the sorbitol cycle of glucose metabolism and NADPH-oxidase under conditions of hyperglycemia leads to the depletion of NADPH and, consequently, the level of GSH. Therefore, the depletion of this cofactor reduces the content of GSH, which is an important factor in protecting against free radicals. ${ }^{21}$ Thus we can explain the reduction of the plasma GSH level in rats under DM. In contrast, the plasma GSH level tends to increase under DM after the administration of extracts of red and yellow fruits of the cornelian cherry. We suppose that there are two main ways explaining these results: the extracts can reduce the production of ROS due to lower blood glucose levels or extracts, namely anthocyanins, and can act as free radical scavengers.

As mentioned before, an excessive number of active forms of oxygen in conditions of diabetes have a cytotoxic effect on the membrane phospholipids, which leads to the formation and accumulation of MDA, a stable end product of lipid peroxidation..$^{15}$ Therefore, our study has shown an increase in the level of TBA-reactive products in blood plasma under DM. The administration of the red cornelian cherry extract leads to a decrease in lipid peroxidation under diabetes. The results suggest that active components in the composition of the red cornelian cherry extract might reduce the level of TBA-reactive products by controlling blood glucose and glycation reactions in addition to their antioxidant activity.

Prolonged hyperglycemia leads to the intensification of non-enzymatic glycosylation of proteins, which also has been implicated in the pathogenesis of diabetic complications. ${ }^{53,54}$ Protein glycation is a spontaneous reaction and is dependent on the half-life of the protein, the degree and duration of hyperglycemia and permeability of the tissue to free glucose. Glycated proteins can be involved in further reactions, which lead to the formation of AGEs. ${ }^{55}$ AGEs are the markers of longterm glycemic control in body tissues. ${ }^{26}$ Protein glycosylation is increased and also stimulated by oxidative stress, which is closely linked to the pathogenesis of diabetic complications as well as the polyol and protein kinase C pathway. Additionally, an increase in AGE concentration is accelerated by the decreased capability to metabolize and/or excrete them. ${ }^{53,56}$ Thus these products also serve as general bio-markers of oxidative stress resulting from carbohydrate and lipid oxidation reactions. ${ }^{57,58}$ The interaction of AGEs with their receptors, RAGE, can alter intracellular signalling, and initiate the release of pro-inflammatory molecules and free radicals, which contribute towards the pathology of DM. ${ }^{55}$ Prevention of the formation or reduction of AGEs has therapeutic potential to slow the progression of diabetic complications. ${ }^{26}$ According to our results, the administration of extracts of red and yellow cornelian cherries led to a decrease in the AGE level in blood plasma. Antioxidant components in the Cornus mas L. fruits provide a compensatory response, leading to the inhibition of stress-sensitive signaling pathways. ${ }^{20}$ Therefore, the treatment with cornelian cherry extracts of red and yellow fruits exhibiting antioxidant activities may be effective in treating or delaying diabetic complications by decreasing oxidative stress.

Like AGEs, AOPPs play a pathogenic role via the RAGE in endothelial cells, induce vascular endothelial dysfunction and accelerate diabetic complications by elevating the level of oxidative stress and inducing the overexpression of inflammatory factors. ${ }^{2,12}$ We observed an increase in AOPPs under DM. AOPPs are dityrosine-containing and crosslinking protein products formed during oxidative stress by combined reactions of plasma proteins (mainly albumin and fibrinogen) with chlori- 
nated oxidants. In addition to the fact that AOPPs are formed by chronic oxidative stress, they can also trigger further stimulation of ROS generation in a variety of cells via NADPH oxidases. The administration of extracts of red and yellow cornelian cherries to animals with DM caused a decrease in this indicator. Therefore, we hypothesized that the effect of the extract of red and yellow fruits on the reduction of the AOPP level might correlate with the marked glycemic control and inhibition of AGE formation in plasma.

The AOPPs via the receptor of RAGE also contribute to progressive islet dysfunction and $\beta$-cell pathophysiology under DM. ${ }^{12}$ Hirsch et al. reported that geniposide, a natural iridoid glycoside, promotes insulin secretion and increases protein levels of GLUT2 in INS-1 cells. Geniposide signals through the GLP-1 receptor promoting PI3 $\mathrm{K}$ activation. PI3Ks and their lipid products in general, and $\mathrm{PI}(3,4) \mathrm{P}_{2} / \mathrm{PI}(3,4,5) \mathrm{P}_{3}$-activated $\mathrm{PKB} / \mathrm{Akt}$ in particular, have been shown to be involved in multiple biological processes including proliferation, differentiation, cell survival, membrane trafficking, cell migration, glucose uptake and metabolism. ${ }^{59}$ Thus geniposide might be an important mediator of the PI3 $\mathrm{K}$ signalling pathway in $\beta$-cells. In addition, iridoid glycoside can have pleiotropic effects in $\beta$-cells, which include the enhancement of glucosedependent insulin release by preserving pancreatic $\beta$-cells, as well as $\beta$-cell proliferation and survival. ${ }^{12,60}$ Since the iridoid content is higher in yellow berries from Cornus mas L. compared with red fruits, the AOPP level decrease is much more effective in the yellow cornelian cherry-treated group. Thus the extract of Cornus mas L. fruits may attenuate the progression of diabetes and diabetes-related complications due to its protective and antioxidant effects on pancreatic $\beta$-cells.

In addition, ROS attack aliphatic amino acids of proteins under condition of oxidative stress. Their keto- and aldehydederivative modifications are formed. Thus we can explain why OMPs increased 1.45-fold in rat blood plasma under DM. The level of $\mathrm{OMP}_{430}$ in plasma was significantly lowered only by yellow fruits of Cornus mas L. compared to the diabetic rats. The $\mathrm{OMP}_{370}$ level was markedly decreased in the red cornelian cherry-administered diabetic group. According to our results, the administration of the red cornelian cherry extract effectively attenuated the formation of oxidative stress markers and similar effects, but being less effective in the yellow cornelian cherry-treated group. We suppose that the red cornelian cherry extract regulates hyperglycemia-induced oxidative stress through a more effective decrease in glucose concentrations in the blood. The results may imply the additive or synergistic effect of anthocyanins and iridoids on the extract content of red fruits of cornelian cherries.

Clinical and experimental studies of blood of people with diabetes and animals with STZ-induced DM attract special attention among all tissues of the body, because it is the most affected by high glucose concentrations. ${ }^{2,8,16,61}$ The accumulation of glucose in the intracellular compartment causes an increase in the non-enzymatic glycosylation of membrane proteins. This process leads to irreversible structural and functional modification of proteins and causes a disruption of the stability of blood cells. As mentioned before, only the treatment with the yellow cornelian cherry of diabetic animals affected the MHC, which depend upon the red cell volume and their saturation degree with hemoglobin. ${ }^{28,62}$ Therefore, the administration of the yellow cornelian cherry extract, which has a higher content of common iridoids compared with the red cornelian cherry extract, shows the normochromic effect in animals with DM. It was also shown that extracts of red and yellow fruits of Cornus mas L. decrease the number of lymphocytes compared with indicators under the pathology. However, no significant changes were observed in the content of blood leukocytes in rats with DM, as well as in animals which were administered extracts. The obtained results have shown that extracts of Cornus mas L. may reduce diabetes-induced abnormalities, which are related to morphological and functional disorders of peripheral blood cells.

The primary signs of the impact of chemicals and therapeutic agents are changes in the functional state of cells and subcellular structures. In order to clarify the peculiarities of the extract of red and yellow cornelian cherry treatment on the blood system status, it was important to investigate the distribution of erythrocytes according to their resistance to the effect of the acid hemolytic agent, which reflected their physiological status. Reduced resistance of RBC to the acid hemolytic agent in rats with DM was found. The analysis of hemolytic curves suggested that a shorter duration of erythrocyte spherulation leading to their destruction was observed in the STZtreated rats, whereas the treatment of diabetic animals with Cornus mas L. partially returned the erythrocyte resistance to acid hemolysis towards the control value. Such changes may be due to the accumulation of lipid peroxidation products and increased oxidative-carbonyl stress under $\mathrm{DM}^{63}$ All these pathological processes result in the structural damage of erythrocytes. It should be noted that the administration of red and yellow cornelian cherry extracts caused an increase in the amount of young red blood cells resistant to acid hemolysis. The administration of Cornus mas L. increased erythrocyte stability to lysis, which can lead to the improvement in blood rheological properties and vascular complications. The antihemolytic effect of Cornus mas L. can be connected not only with the antioxidant capacity of anthocyanins and polyphenols in the composition of extracts, but also with a decrease in the glycated hemoglobin level. We noticed a decrease in blood glucose levels and plasma concentrations of OMPs, AGEs, AOPPs and TBARS in cornelian cherry-treated groups of animals, whereas the level of GSH increased. The obtained results have shown that the extracts from Cornus mas L. may have antidiabetic effects and reduce diabetes-induced abnormalities that are related to morphological and functional disorders of peripheral blood cells.

\section{Conclusions}

Oral administration of extracts of fruits of Cornus mas L. reduced the decline in body weight and prevented hyperglyce- 
mia. Otherwise, we noticed a decrease in levels of TBA-reactive substances, OMPs of neutral nature and the glycated hemoglobin level in rats' blood plasma only after the administration of the extract of red cornelian cherry, while the reduction of AGE and AOPP levels was shown in both extract-treated groups of animals. A decrease in markers of carbonyl-oxidative stress indicates effective protective components of the cornelian cherry against oxidative damage. The administration of the extract of yellow fruits of Cornus mas L. leads to an increase in the level of $\mathrm{GSH}$ and $\mathrm{MCH}$ in diabetic rats. The antioxidants, iridoids and polyphenols, which are present in extracts of cornelian cherries, neutralize active forms of oxygen and inhibit lipid peroxidation - the main factors of blood cell structure destruction in the conditions of DM. The study has shown that Cornus mas L. may be a potential therapeutic agent or a dietary supplement for hyperglycemia associated with diabetic complications.

\section{Conflicts of interest}

The authors declare that there is no actual or potential conflict of interest, including any financial, personal or other conflicts.

\section{Acknowledgements}

The publication was supported by the Wrockaw Centre of Biotechnology, under the programme of the Leading National Research Centre (KNOW - Poland) during 2014-2018.

The authors would like to thank Dr Oleh Lushchak from Vasyl Stefanyk National University in Ivano-Frankivs, Ukraine and SME's of BTRP Ukraine Science Writing Mentorship Program for his advice and comments.

The authors would like to acknowledge the United States Department of Defense, Defense Threat Reduction Agency (DTRA), and Cooperative Biological Engagement Program (CBEP) for their support to develop this manuscript. While DTRA/CBEP did not support the research described in this publication, the Program supported the presentation of this research in an international forum and supported grantsmanship/science writing training related to the development of this manuscript. The contents of this publication are the responsibility of the authors and do not necessarily reflect the views of DTRA or the United States Government.

All animal procedures were performed in accordance with the Guidelines for Care and Use of Laboratory Animals of Ivan Franko National University of Lviv and experiments were approved by the Animal Ethics Committee of Department of Biochemistry of the Faculty of Biology.

\section{References}

1 S. Putta and E. K. Kilari, A review on methods of estimation of advanced glycation end products, World J. Pharm. Res., 2015, 4(9), 689-699.
2 V. R. Preedy, Diabetes: Oxidative Stress and Dietary Antioxidants, Elsevier Inc., All rights reserved, 2014, p. 280, DOI: 10.1016/C2012-0-02421-0.

3 http://www.who.int/news-room/fact-sheets/detail/the-top-10causes-of-death.

4 M. Lenzen, The mechanisms of alloxan- and streptozotocin-induced diabetes, Diabetologia, 2008, 1, 216-222.

5 C. O. Eleazu, K. C. Eleazu, S. Chukwuma and U. N. Essien, Review of the mechanism of cell death resulting from streptozotocin challenge in experimental animals, its practical use and potential risk to humans, J. Diabetes Metab. Disord., 2013, 12, 60-66.

6 J. Gronholma and M. J. Lenardoa, Novel diagnostic and therapeutic approaches for autoimmune diabetes - a prime time to treat insulitis as a disease, Clin. Immunol., 2015, 156(2), 109-118.

7 B. L. Furman, Streptozotocin-induced diabetic models in mice and rats, Curr. Protoc. Pharmacol., 2015, 70(5.47), $1-20$.

8 S. N. Goyal, N. M. Reddy, K. R. Patil, K. T. Nakhate, S. Ojha, C. R. Patil and Y. O. Agrawal, Challenges and issues with streptozotocin-induced diabetes - A clinically relevant animal model to understand the diabetes pathogenesis and evaluate therapeutics, Chem.-Biol. Interact., 2016, 244, 49-63.

9 A. Aboonabi, A. Rahmat and F. Othman, Antioxidant effect of pomegranate against streptozotocin-nicotinamide generated oxidative stress induced diabetic rats, Toxicol. Rep., 2014, 1, 915-922.

10 I. West, Radicals and oxidative stress in diabetes, Diabetic Med., 2000, 17, 171-180.

11 M. Atalay and D. E. Laaksonen, Diabetes, oxidative stress and physical exercise, J. Sport. Sci. Med., 2002, 1(1), 1-14.

12 Z. Zhang, L. Yang, L. Lei, R. Chen, H. Chen and H. Zhang, Glucagon-like peptide-1 attenuates advanced oxidation protein product-mediated damage in islet microvascular endothelial cells partly through the RAGE pathway, Int. J. Mol. Med., 2016, 38(4), 1161-1169.

13 E. Araki and T. Nishikawa, Oxidative stress: a cause and therapeutic target of diabetic complications, J. Diabetes Invest., 2010, 1, 90-96.

14 A. P. Rolo and C. M. Palmeira, Diabetes and mitochondrial function: role of hyperglycemia and oxidative stress, Toxicol. Appl. Pharmacol., 2006, 212, 167-178.

15 D. Gao, Q. Li, Z. Gao and L. Wang, Antidiabetic effects of the Corni Fructus extract on streptozotocin-induced diabetic rats, Yonsei Med. J., 2012, 53(4), 691-700.

16 K. C. Herold, D. A. Vignali, A. Cooke and J. A. Bluestone, Type 1 diabetes: translating mechanistic observations into effective clinical outcomes, Nat. Rev. Immunol., 2013, 13(4), 243-256.

17 C. H. Park, E. J. Cho and T. Yokozawa, Protection against hypercholesterolemia by the Corni Fructus extract and its related protective mechanism, J. Med. Food, 2009, 12, 973-981.

18 C. H. Park, N. Yamabe, J. S. Noh, K. S. Kang, T. Tanaka and T. Yokozawa, The beneficial effects of morroniside on the 
inflammatory response and lipid metabolism in the liver of db/db mice, Biol. Pharm. Bull., 2009, 32, 1734-1740.

19 C. H. Park, J. S. Noh, T. Tanaka and T. Yokozawa, Effects of morroniside isolated from Corni Fructus on renal lipids and inflammation in type 2 diabetic mice, J. Pharm. Pharmacol., 2010, 62, 374-380.

20 C. H. Park, J. S. Noh, J. H. Kim, T. Tanaka, Q. Zhao, K. Matsumoto, N. Shibahara and T. Yokozawa, Evaluation of morroniside, iridoid glycoside from Corni Fructus, on diabetes-induced alterations such as oxidative stress, inflammation, and apoptosis in the liver of type 2 diabetic db/db mice, Biol. Pharm. Bull., 2011, 34(10), 1559-1565.

21 T. Sozanski, A. Z. Kucharska, A. Rapak, D. Szumny, M. Trocha, A. Merwid-Lad, S. Dzimira, T. Piasecki, N. Piorecki, J. Magdalan and A. Szelag, Iridoid-loganic acid versus anthocyanins from the Cornus mas fruits (cornelian cherry): Common and different effects on diet-induced atherosclerosis, PPARs expression and inflammation, Atherosclerosis, 2016, 254, 151-160.

22 T. Sozanski, A. Z. Kucharska, D. Szumny, J. Magdalan, A. Merwid-Lad, B. Nowak, N. Piorecki, S. Dzimira, A. Jodkowska, A. Szelag and M. Trocha, Cornelian cherry consumption increases the L-arginine/ADMA ratio, lowers ADMA and SDMA levels in the plasma, and enhances the aorta glutathione level in rabbits fed a high-cholesterol diet, J. Funct. Foods, 2017, 34, 189-196.

23 A. Z. Kucharska, Active Compounds of Cornelian Cherry Fruit (Cornus mas L.), WUP, Wrocław, 2012, http://www.dbc.wroc. $\mathrm{pl} /$ Content/18811/82 Zwiazki aktywne owocow derenia Kucharska A.pdf.

24 B. J. West, S. Deng, C. J. Jensen, A. K. Palu and L. F. Berrio, Antioxidant, toxicity, and iridoid tests of processed Cornelian cherry fruits, Int. J. Food Sci. Technol., 2012, 47, 1392-1397.

25 A. Z. Kucharska, A. Sokół-Łętowska, J. Oszmiański, N. Piórecki and I. Fecka, Iridoids, phenolic compounds and antioxidant activity of edible honeysuckle berries (Lonicera caerulea var. kamtschatica Sevast.), Molecules, 2017, 22, E405.

26 N. Yamabe, K. S. Kang, Y. Matsuo, T. Tanaka and T. Yokozawa, Identification of antidiabetic effect of iridoid glycosides and low molecular weight polyphenol fractions of Corni Fructus, a constituent of Hachimi-jio-gan, in streptozotocin-induced diabetic rats, Biol. Pharm. Bull., 2007, 30(7), 1289-1296.

27 S. T. Yeh, Using trapezoidal rule for the area under a curve calculation. Proceedings of the Twenty-Seventh Annual SAS. User Group International (SUGI) Conference, 2002, vol. 27, pp. 229-237.

28 I. V. Brodyak and N. O. Sybirna, Methods of research of blood system, Lviv, 2018, p. 108.

29 T. Y. Vitak, S. P. Wasser, E. Nevo and N. O. Sybirna, The effect of the medicinal mushrooms Agaricus brasiliensis and Ganodermalucidum (higher basidiomycetes) on the erythron system in normal and streptozotocin-induced diabetic rats, Int. J. Med. Mushrooms, 2015, 17, 277-286.
30 B. Melekh, I. Ilkiv, A. Lozynskyi and A. Sklyarov, Antioxidant enzyme activity and lipid peroxidation in rat liver exposed to celecoxib and lansoprazole under epinephrine-induced stress, J. Appl. Pharm. Sci., 2017, 7, 94-99.

31 E. Augustyniak, A. Adam, K. Wojdyla, A. Rogowska-Wrzesinska, R. Willetts, A. Korkmaz, M. Atalay, D. Weber, T. Grune, C. Borsa, D. Gradinaru, R. Chand Bollineni, M. Fedorova and H. Griffiths, Validation of protein carbonyl measurement: a multi-centre study, Redox Biol., 2015, 4, 149-157.

32 A. Demkovych, Y. Bondarenko and P. Hasiuk, Oxidative modification of proteins in the process of experimental periodontitis development, Interv. Med. Appl. Sci., 2017, 9(4), 218-221.

33 S. I. Rizvi and M. A. Zaid, Intracellular reduced glutathione content in normal and type 2 diabetic erythrocytes: effect of insulin and (-) epicatechin, J. Physiol. Pharmacol., 2001, 52(3), 483-488.

34 V. Witko-Sarsat, M. Friedlander, C. Capeillère-Blandin, T. Nguyen-Khoa, A. T. Nguyen, J. Zingraff, P. Jungers and B. Descamps-Latscha, Advanced oxidation protein products as a novel marker of oxidative stress in uremia, Kidney Int., 1996, 49(5), 1304-1313.

35 M. Kalousová, T. Zima, V. Tesař, J. Škrha and S. Štípek, Determination of advanced glycation end-products and advanced oxidation protein products, Klin. Biochem. Metab., 2002, 10, 11-16.

36 A. Z. Kucharska, A. Szumny, A. Sokół-Łetowska, N. Piórecki and S. V. Klymenko, Iridoids and anthocyanins in cornelian cherry (Cornus mas L.) cultivars, J. Food Compos. Anal., 2015, 40, 95-102.

37 S. Deng, B. J. West and C. J. Jensen, UPLC-TOF-MS characterization and identification of bioactive iridoids in Cornus mas fruits, J. Anal. Methods Chem., 2013, 2013, 710972.

38 A. M. Pawlowska, F. Camangi and A. Braca, Quali-quantitative analysis of flavonoids of Cornus mas L. (Cornaceae) fruits, Food Chem., 2010, 119, 1257-1261.

39 K. Shapiro and W. C. Gong, Natural products used for diabetes, J. Am. Pharm. Assoc., 2002, 42, 217-226.

40 O. Ozsoy-Sacan, O. Karabulut-Bulan, S. Bolkent, R. Yanardag and Y. Ozgey, Effects of chard (Beta vulgaris L. var cicla) on the liver of the diabetic rats: a morphological and biochemical study, Biosci., Biotechnol., Biochem., 2004, 68, 1640-1648.

41 T. Yokozawa, N. Yamabe, H. Y. Kim, K. S. Kang, J. M. Hur, C. H. Park and T. Tanaka, Protective effects of morroniside isolated from Corni Fructus against renal damage in streptozotocin-induced diabetic rats, Biol. Pharm. Bull., 2008, 31, 1422-1428.

42 N. Yamabe, K. S. Kang, C. H. Park, T. Tanaka and T. Yokozawa, 7-O-Galloyl-D-sedoheptulose is a novel therapeutic agent against oxidative stress and advanced glycation end products in the diabetic kidney, Biol. Pharm. Bull., 2009, 32, 657-664.

43 H. Madariaga, P. C. Lee, L. A. Heitlinger and E. Lebenthal, Effects of graded $\alpha$-glucosidase inhibition on sugar absorption in vivo, Dig. Dis. Sci., 1988, 33, 1020-1024. 
44 M. Jung, M. Park, H. C. Lee, Y. H. Kang, E. S. Kang and S. K. Kim, Antidiabetic agents from medicinal plants, Curr. Med. Chem., 2006, 13, 1203-1218.

45 A. Sarikaphuti, T. Nararatwanchai, T. Hashiguchi, T. Ito, S. Thaworanunta, K. Kikuchi, Y. Oyama, I. Maruyama and S. Tancharoen, Preventive effects of Morus alba L. anthocyanins on diabetes in Zucker diabetic fatty rats, Exp. Ther. Med., 2013, 6(3), 689-695.

46 A. Jennings, A. A. Welch, T. Spector, A. Macgregor and A. Cassidy, Intakes ofanthocyanins and flavones are associated with biomarkers of insulin resistance and inflammation in women, J. Nutr., 2014, 144(2), 202-228.

47 A. Smeriglio, D. Barreca, E. Bellocco and D. Trombetta, Chemistry, pharmacology and health benefits of anthocyanins, Phytother. Res., 2016, 30(8), 1265-1286.

48 M. Pinent, M. Blay, M. C. Blade, M. J. Salvado, L. Arola and A. Ardevol, Grape seed-derived procyanidins have an antihyperglycemic effect in streptozotocin-induced diabetic rats and insulinomimetic activity in insulin-sensitive cell lines, Endocrinology, 2004, 145, 4985-4990.

49 S. Asgary, M. Rafieian-Kopaei, F. Shamsi, S. Najafi and A. Sahebkar, Biochemical and histopathological study of the anti-hyperglycemic and anti-hyperlipidemic effects of cornelian cherry (Cornus mas L.) in alloxan-induced diabetic rats, J. Complementary Integr. Med., 2014, 11(2), 63-69.

50 A. C. Guyton and J. E. Hall, Textbook of Medical Physiology, W.B. Saunders Company, Philadelphia, $10^{\text {th }}$ edn, 2000, pp. 754-763.

51 V. R. Drel and N. Sybirna, Protective effects of polyphenolics in red wine on diabetes associated oxidative/nitrative stress in streptozotocin-diabetic rats, Cell Biol. Int., 2010, 34, 1147-1153.

52 S. V. Reddy, A. K. Tiwari, U. S. Kumar, R. J. Rao and J. M. Rao, Free radical scavenging, enzyme inhibitory constituents from antidiabetic Ayurvedic medicinal plant Hydnocarpus wightiana Blume, Phytother. Res., 2005, 19, 277-281.

53 J. Bohlender, S. Franke, G. Stein and G. Wolf, Advanced glycation end products and the kidney, Am. J. Physiol. Renal Physiol., 2005, 289, F645-F659.
54 K. Fukami, S. Ueda, S. Yamagishi, S. Kato, Y. Inagaki, M. Takeuchi, Y. Motomiya, R. Bucala, S. Iida, K. Tamaki, T. Imaizumi, M. E. Cooper and S. Okuda, AGEs activate mesangial TGF-beta-Smad signaling via an angiotensin II type I receptor interaction, Kidney Int., 2004, 66, 2137-2147.

55 N. Ahmed, Advanced glycation endproducts - role in pathology of diabetic complications, Diabetes Res. Clin. Pract., 2005, 67(1), 3-21.

56 M. C. Thomas, J. M. Forbes and M. E. Cooper, Advanced glycation end products and diabetic nephropathy, Am. J. Ther., 2005, 12, 562-572.

57 W. Koito, T. Araki, S. Horiuchi and R. Nagai, Conventional antibody against Nepsilon-(carboxymethyl)lysine (CML) shows cross-reaction to Nepsilon-(carboxyethyl)lysine (CEL): immunochemical quantification of CML with a specific antibody, J. Biochem., 2004, 136, 831-837.

58 M. L. M. Lieuw-A-Fa, V. W. M. van Hinsbergh, T. Teerlink, R. Barto, J. Twisk, C. D. A. Stehouwer and C. G. Schalkwijk, Increased levels of $\mathrm{N}($ epsilon)-(carboxymethyl)lysine and $\mathrm{N}$ (epsilon)-(carboxyethyl)lysine in type 1 diabetic patients with impaired renal function: correlation with markers of endothelial dysfunction, Nephrol., Dial., Transplant., 2004, 19, 631-636.

59 E. Hirsch, C. Costa and E. Ciraolo, Phosphoinositide 3-kinases as a common platform for multi-hormone signaling, J. Endocrinol., 2007, 194, 243-256.

60 S. M. Jang, S. T. Yee, J. Choi, M. S. Choi, G. M. Do, S. M. Jeon, J. Yeo, M. Kim, K. I. Seo and M. K. Lee, Ursolic acid enhances the cellular immune system and pancreatic $\beta$-cell function in streptozotocin-induced diabetic mice fed a high-fat diet, Int. Immunopharmacol., 2009, 9, 113-119.

61 M. Bryszewska, I. B. Zavodnik, A. Niekurzak and K. Szosland, Oxidative processes in red blood cells from normal and diabetic individuals, Biochem. Mol. Biol. Int., 1995, 37, 345-354.

62 T. D. Johnson-Wimbley and D. Y. Graham, Diagnosis and management of iron deficiency anemia in the 21st century, Ther. Adv. Gastroenterol., 2011, 4(3), 177-184.

63 D. Bonnefont-Rousselot, J. P. Bastard, M. C. Jaudon and J. Delattre, Consequences of the diabetic status on the oxidant/ antioxidant balance, Diabetes Metab., 2000, 26, 163-176. 